Neuro View Box

Prabin Shrestha, MD, PhD

Department of Neurosurgery

B\&B Hospital, Gwarko

Lalitpur, Nepal

Anish M Singh, MS

Department of Neurosurgery

B\&B Hospital, Gwarko

Lalitpur, Nepal

Address for correspondence:

Prabin Shrestha, MD, PhD

Department of Neurosurgery

B\&B Hospital, Gwarko

Lalitpur, Nepal

Email: prabinshrestha@hotmail.com

Received, 13 October, 2016

Accepted, 26 October, 2016

$\mathrm{S}$ chwannomas are the most common tumors of spine. Dumbbell schwannomas are more commonly found in cervical spine. Complete excision of swchnnoma is mandatory to prevent its recurrence. However, at times it becomes difficult and rather impossible in certain cases of giant schwannomas. It is more so when there is no intraopertive neurophysiological monitoring.

In this regard here we present 11-year-old boy with giant dumbbell schwannoma at the level of C2 cervical spine. The boy presented with progressive left upper limb weakness. He started having a lump, which got more prominent with time, on the back surface of left upper neck. MRI showed mass at $\mathrm{C} 2$ starting from left intradural space extending to extraforaminal space. The mass was giant measuring about $100 \mathrm{~mm}$ and was homogenously enhanced with contrast (Figure 1).

Surgery was planned through extraforaminal approach. A curvilinear incision was given with the vertical limb of incision in the midline. Extraforaminal giant mass was approached first. Surrounding dissection of the mass was done. Foramen was approached and foraminotomy was done along with small hemilaminotomy of $\mathrm{C} 2$ on left side. Total mass was excised in block through the foramen doing durotomy.

Neurophysiological monitoring is essential intraoperatively while operating on such cases to minimize possible neurological deficit. ${ }^{2}$ However, in our context,
Nepal Journal of Neuroscience 13:88-88, 2016

\section{Complete Excision of Giant Dumbbell Schwannoma without Neurophysiological Monitoring}

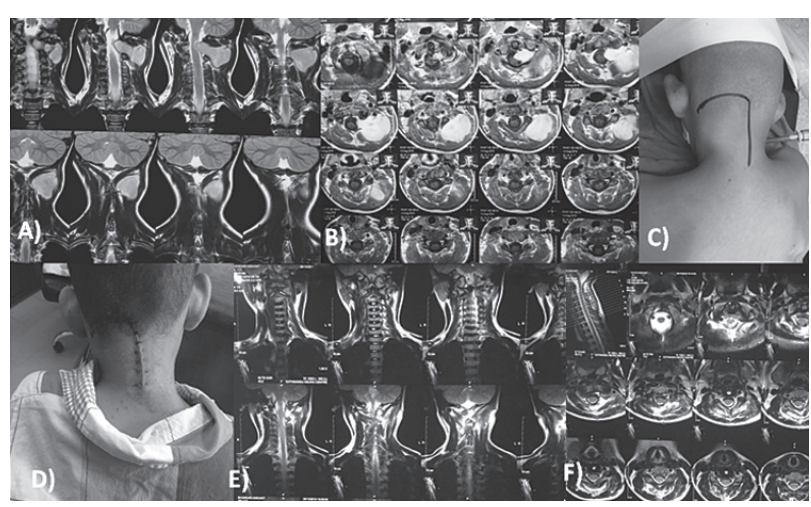

Figure 1: A, B) Preoperative MRO T1W with contrst Coronal and Axial view showing giant dumbbell schwannoma at C2 level on left side, C) intraoperative position and incision mark, D) post operative wound, $E, F)$ post operative MRI showing complete excision of mass

since it is not yet available in Nepal, we did complete excision without any monitoring. Surgery was done with through understanding of local anatomy as depicted by MRI. As a result neurovascular structures were spared and the boy improved significantly after surgery.

Such surgical procedure often requite instrumentation like pedicle or lateral mass screw to stabilize spine as facet joint is often disrupted in such cases. ${ }^{1,3}$ However, in our case we didn't disrupt facet joint, rather did small foraminotomy and small hemilaminotomy through which mass was completely excised.

\section{Reference}

1. McCormick PC. Resection of a cervical dumbbell schwannoma with stabilization through a single stage extended posterior approach. Neurosurg Focus 37, Suppl 27, 2014

2. Safaee MM, Lyon R, Barbaro NM, et al. Neurological outcomes and surgical complications in 221 spinal nerve sheath tumors. J Neurosurg Spine 29:1-9, 2016

3. Vergara P. A novel less invasive technique for the excision of large intra- and extra- dural dumbbell lumbar schwannomas: the "dual approach". World Neurosurg, 2016 Aug 6. 